\title{
PENERAPAN CSR (CORPORATE SOCIAL RESPONSIBILITY) PADA PERUSAHAAN AIR MELYA CV. BAGAS TIRTA UTAMA DALAM KAITANNYA DENGAN PENINGKATAN LABA USAHA PERUSAHAAN
}

\author{
I Gede Giri Darmawan \\ Jurusan Akuntansi Program Diploma III, \\ Universitas Pendidikan Ganesha,Singaraja \\ e-mail : giridarmawan@gmail.com
}

\begin{abstract}
Abstrak
Penelitian ini bertujuan untuk mengetahui : 1) Penerapan CSR (Corporate Social Responsibility) Pada Perusahaan Air Melya CV. BAGAS TIRTA UTAMA, 2) Peningkatan Laba Usaha Perusahaan 3) Implementasi CSR terhadap kehidupan masyarakat.

Penelitian ini termasuk jenis penelitian deskriptif kualitatif. Subjek penelitian ini adalah CV. Bagas Tirta Utama, dengan objek penelitian Penerapan CSR (Corporate Social Responsibility) Pada Perusahaan Air Melya CV. BAGAS TIRTA UTAMA Dalam Kaitannya Dengan Peningkatan Laba Usaha Perusahaan. Teknik pengumpulan data yang digunakan adalah wawancara.

Hasil penelitian menunjukan bahwa 1) CV. Bagas Tirta Utama menerapkan CSRnya dalam bentuk program-programnya dengan bermitra bersama masyarkat dan karyawan. 2) Program CSR tersebut juga dilaksanakan untuk melestarikan lingkungan dan menjaga perekonomian masyarakat. 3) Dari serangkaian kegiatan CSR tersebut perusahaan juga dapat meningkatkan konsumen dan laba usahanya, dan merupakan suatu upaya perusahaan CV. Bagas Tirta Utama dalam menjalin hubungan antara perusahaan, karyawan, dan masyarkat, serta lingkungan sekitar perusahaan tersebut.

Kata Kunci : Penerapan CSR, Peningkatan Laba Usaha.
\end{abstract}

\begin{abstract}
This study aims to determine: 1) Implementation of CSR (Corporate Social Responsibility) At Water Company Melya CV. BAGAS TIRTA UTAMA, 2) Increase Operating Income Companies 3) Implementation of CSR on community life.

This research is included in the type of qualitative descriptive research. The subject of this research is CV. Bagas Tirta Utama, with the object of research Implementation of CSR (Corporate Social Responsibility) On Water Company Melya CV. BAGAS TIRTA UTAMA In Relation With Increased Operating Profit. Data collection techniques used are interviews. Data were analyzed by qualitative descriptive analysis technique.

The results showed that 1) CV. Bagas Tirta Utama applies its CSR in the form of its programs by partnering with the community and employees. 2) The CSR program is also implemented to preserve the environment and maintain the economy of the community. 3) From a series of CSR activities the company can also increase the consumer and profit of his business, and is an effort of CV company. Bagas Tirta Utama in establishing relationships between companies, employees, and society, and the environment around the company.
\end{abstract}

Key words: Implementation of CSR, Increase Operating Income.

\section{PENDAHULUAN}

Tujuan umum dari sebuah usaha didirikan adalah untuk mencari laba. Laba secara umum adalah selisih dari pendapatan di atas biaya-biayanya dalam jangka waktu tertentu. Laba sering digunakan sebagai suatu dasar untuk pengenaan pajak, kebijakan deviden, pedoman investasi serta pengambilan keputusan dan unsur prediksi (Harnanto, 2003: 444). Laba seuatu perusahaan merupakan gambaran perusahaan mengenai kinerja yang dicapai 
dari proses transaksi umum yang dilakukan perusahaan selama periode tertentu, dan laba dapat dijadikan suatu indikator bagi para pemangku kepentingan untuk menilai sejauh mana kinerja manajemen dalam mengelola suatu perusahaan. Meski tujuan utama perusahaan adalah menghasilkan laba, sebuah perusahaan tidak dapat lepas dari masyarakat, hal ini disebabkan pendiri dan pemilik sebuah perusahaan adalah individu-individu anggota masyarakat serta tujuan menghasilkan keuntungan tidak mungkin tercapai tanpa adanya masyarakat yang menjadi pasar dari peroduksinya. Karena sebuah kegiatan bisnis tidak dapat lepas dari masyarakat, kegiatan bisnis sudah pasti membawa dampak bagi masyarakat dan elemen-elemen yang ada didalamnya serta lingkungan hidup di masyarakat.

Pelaksanaan CSR menunjukan kepedulian perusahaan terhadap kepentingan pihakpihak lain secara lebih luas dari pada hanya sekedar kepentingan perusahaan saja.

Perkembangan suatu perusahaan tak terlepas dari hubungan eratnya dengan konsumen, dan keadaan lingkungan baik dari segi daerah dan di Negara mana perusahaan tersebut berdiri, oleh karenanya semakin baik pelayanan atau hubungan suatu perusahaan terhadap konsumen maka akan semakin besar pula kesempatan perusahaan tersebut untuk terus berkembang menjadi sebuah perusahaan besar. Perusahaan sebagai pelaku bisnis atau korporasi merupakan suatu badan yang mempunyai kegiatan tertentu untuk mencapai tujuan. Biasanya disamping mencari laba, tujuan perusahaan mencakup pertumbuhan yang terus-menerus (growth), kelangsungan hidup (survival), dan kesan positif dimata publik (image). Untuk itu dibutuhkan suatu sarana yang dapat memberikan informasi mengenai aspek sosial, lingkungan dan keuangan secara sekaligus. Sarana tersebut dikenal dengan nama laporan keberlanjutan atau sustainability reporting. Sustainability reporting adalah praktek pengukuran, pengungkapan dan upaya akuntabilitas dari kinerja organisasi dalam mencapai tujuan pembangunan berkelanjutan kepada stakeholder internal maupun eksternal.

Corporate Social Responsibility merupakan salah satu bentuk sustainability reporting yang memberikan keterangan tentang berbagai aspek-aspek perusahaan mulai dari aspek sosial, lingkungan dan keuangan sekaligus yang tidak dapat dijelaskan secara tersirat oleh suatu laporan keuangan perusahaan saja. Lebih jauh, dalam Corporate Social Responsibility yang diungkapkan, perusahaan dalam menjelaskan tentang aspek Ekonomi, Lingkungan, Tenaga Kerja, Hak asasi manusia, Sosial, dan Tanggung jawab Produk. Namun dalam lingkup pembahasan Corporate Social Responsibility, terdapat beberapa teori dan pendekatan yang berbeda, dimana penelitian-penelitian tersebut sangat rumit dan dalam beberapa kasus sangat kontradiksi, yang digunakan untuk menjelaskan motivasi perusahaan yang mengarah pada sustainability behavior (Chand dan Fraser, 2006).

Pada periode-periode sebelum tahun 2007 pengungkapan Corporate Social Responsibility atau tanggung jawab sosial perusahaan masih sekedar bersifat sukarela, untuk itu pemerintah Indonesia pada tahun 2007 mengeluarkan Undang-undang Perseroan Terbatas No.40 Pasal 74 tahun 2007, yang pasal (1) berbunyi Perseroan yang menjalankan kegiatan usahanya di bidang dan/atau berkaitan dengan sumber daya alam wajib melaksanakan Tanggung Jawab Sosial dan Lingkungan. Dan pasal (2) Tanggung Jawab Sosial dan Lingkungan sebagaimana dimaksud pada ayat (1) merupakan kewajiban Perseroan yang dianggarkan dan diperhitungkan sebagai biaya Perseroan yang pelaksanaannya dilakukan dengan memperhatikan kepatutan dan kewajaran, atau secara singkat menyiratkan bahwa perusahaan yang melakukan kegiatan usaha di bidang/berkaitan dengan sumber daya alam wajib melakukan tanggung jawab sosial dan lingkungan.

Undang-undang tersebut mewajibkan industri atau korporasi-korporasi untuk melaksanakannya, tetapi kewajiban ini bukan merupakan suatu beban yang memberatkan. Perlu diingat bahwa pembangunan suatu negara bukan hanya tanggung jawab pemerintah 
dan industri saja, tetapi setiap insan manusia berperan untuk mewujudkan kesejahteraan sosial dan pengelolaan kualitas hidup masyarakat.

Sehingga, berdasarkan uraian diatas maka penulis dapat merumuskan masalah mengenai bagaiman penerapan Corporate Social Responsibility pada perusahaan CV. Bagas Tirta Utama dalam kaitannya dengan peningkatan laba usaha perusahaan dengan tujuan Untuk mengetahui bagaimana penerapan CSR (Corporate Sicial Responcibility) pada perusahaan air melya, dan untuk mengetahui peranan CV. BAGAS TIRTA UTAMA terhadap kehidupan sosial dan ekonomi masyarakat di sekitar perusahaan.

\section{Metode Penelitian}

Penelitian ini dilakukan pada perusahaan air minum kemasan organik "Melya" CV. BAGAS TIRTA UTAMA jalan raya wanagiri Sukasada Buleleng Bali dengan subyek penelitian ini adalah perusahaan air minum kemasan organik "Melya" CV. BAGAS TIRTA UTAMA dan obyek penelitiannya adalah penerapan CSR (Corporate Social Responsibility) pada perusahaan air Melya CV. BAGAS TIRTA UTAMA dalam kaitannya dengan peningkatan laba usaha perusahaan. Jenis data yang digunakan adalah data primer. Data primer merupakan data yang diperoleh secara langsung melalui metode wawancara, sehingga menghasilkan data kualitatif. Metode pengumpulan data yang digunakan dalam penelitian ini adalah wawancara Yaitu pengumpulan data dengan cara mengadakan tanya jawab secara langsung kepada pihak-pihak yang bersangkutan pada CV. BAGAS TIRTA UTAMA mengenai penerpan CSR terkait dalam meningkatkan laba usaha perusahaan. Untuk memecahkan masalah yang dihadapi, maka teknik analisis data yang digunakan adalah teknik analisis deskriptif kualitatif. Analisis deskriftif kualitatif yaitu menguraikan atau menjabarkan dan menjelaskan segala informasi yang berkaitan dengan penerapan CSR dalam kaitannya memperoleh laba usaha pada CV. BAGAS TIRTA UTAMA.

\section{Hasil Penelitian dan Pembahasan}

Berdasarkan analisis dan metode penelitian yang digunakan maka Penerapan program CSR merupakan salah satu bentuk implementasi dari konsep tata kelola perusahaan yang baik. Melaksanakan tata kelola yang baik, prilaku dari pebisnis mempunyai arah dalam mengatur hubungan dengan seluruh pemangku kepentingan stakeholder. Kepentingan semua stakeholder dapat dipenuhi secara propesional, mencegah kesalahnkesalahan yang signifikan dalam strategi korporasi dan memastikan kesalahan-kesalahan yang terjadi dapat diperbaiki dengan segera.

Setiap pelaksanaan CSR tidak terlepas dari keempat pilar yang menjadi landasan dalam penerapan CSR. Penerapan keempat pilar tersebut oleh Air Melya dilaksanakan pada bisnisnya dengan jujur dan sejalan dengan hokum yang berlaku. Pelaksanaan CSR Air melya mengacu pada pasal 74 undang-undang No. 40 tahun 2007 tentang Perseroan Terbatas. Berikut program-program yang dijalankan oleh perusahaan Air Melya: (1) Bidang Sosial yaitu: CSR Air Melya memberikan kontribusi sebagai wujud perusahaan peduli lingkungan. Dengan ini perusahaan CV. Bagas Tirta Utama melakukan pembersihan dan penanaman pohon bunga di pinggir jalan desa wanagiri. Namun kegiatan penyadaran dan peduli terhadap lingkungan ini tidak berhenti pada masyarakat di sekitar desa wanagiri saja tetapi juga karyawan Air Melya yang dilibatkan langsung dalam kegiatan ini. Karena kegiatan ini juga mampu menyadarkan masyarakat serta karyawan untuk bersama-sama melakukan penyelamatan lingkungan serta membangun komunikasi yang baik. Peduli terhadap lingkungan sekitar atau gotong royong ini dilaksanakan setiap sebulan sekali oleh perusahaan Air Melya.

Selain itu perusahaan juga memberikan bantuan berupa uang tunai ataupun sembako kepada masyarakat kurang mampu yang ada di wilayah desa wanagiri, guna 
meningkatkan rasa kepedulian perusahaan CV. Bagas Tirta Utama terhadap masyarakat. Bantuan ini biasanya dilaksanakan setiap tahunnya.

Adanya harapan masyarakat ke depan bahwa CSR Air Melya mempunyai programprogram lain yang dapat bermanfaat bagi masyarakat adalah salah satu bukti bahwa CSR Air Melya melalui programnya dirasakan oleh masyarakat sebagai wuud nyata. (2) Bidang Ekonomi yaitu: Kontribusi perusahaan Air Melya yaitu mampu membuka lapangan pekerjaan bagi masyarakat sesuai dengan kemampuan dan bidangnya masing-masing. Sehingga nantinya mampu mengurangi angka pengangguran.

Selain itu perusahaan Air Melya juga melakukan pengembangan kawasan dengan memberikan bantuan kepada masyarakat dalam mengelola kawasan wisata alam yang ada di sekitar desa wanagiri. Sehingga mampu memberikan daya tarik konsumen maupun wisatawan. Program-program tersebut dilakukan melalui upaya pemberdayaan masyarakat, dengan menciptakan pola partisipatif dalam proses pembangunan dan menempatkan masyarakat setempat sebagai subjek dalam proses pembangunan. Hasilnya banyak manfaat yang didapat oleh masyarakat melalui kegiatan tersebut. Perusahaan melakukan kegiatan ini mulai tahun 2014 smpai sekarang, dan dampak positif yang di dapat perusahaan melalui program-program ekonomi tersebut membuat perusahaan menjadi lebih dikenal oleh masyarakat luas sehingga perusahaan mampu meningkatkan laba perusahaannya dan juga masyarakat disekitar perusahaan merasa di untungkan. (3) Bidang Keagamaan yaitu: Kontribusi Air Melya memberikan sumbangan sukarela kepada masyarakat, yang memiliki upacara kematian ataupun upacara keagamaan lainnya. Guna meningkatkan ikatan tali persudaraan perusahaan dengan masyarkat sekitar.

Selain itu juga perusahaan memberikan sumbangan kepada desa adat dalam hal pembangunan tempat upacara (pura), maupun upacara di pura yang ada di sekitar desa wanagiri. Dengan adanya bantuan tersebut perusahaan mampu mengurangi beban masyarakat dalam iuran pembangunan tempat suci maupun upacara tersebut.

Dengan kegiatan ini perusahaan mampu memberikan kontribusi yang baik terhadap masyarakat. Dengan demikian melalui kegiatan keagamaan perusahaan juga akan dilihat oleh banyak orang, manfaatnya perusahaan mampu mencari konsumen dengan banyak dan perusahaan juga dapat meningkatkan labanya. Kegiatan keagamaan ini dilakukan hampir setiap tahunnya.

Tanggung jawab sosial perusahaan adalah komitmen berklanjutan perusahaan untuk berprilaku secara etis dan memberikan kontribusi pada pembangunan ekonomi untuk meningkatkan kualitas hidup ditempat kerja dan keluarganya serta komunitas lokal dan masyarakat yang lebih luas. Dari definisi ini, CSR secara internal merupakan kebijakan, praktek dan program yang terintegrasi dengan aktivitas perusahaan, rantai nilai dan dalam proses pengambilan keputusan.

Corporate Social Responsibility menjadi salah satu faktor yang mempengaruhi nilai perusahaan karena salah satu dasar pemikiran yang melandasi Corporate Social Responsibility yang pada saat ini dianggap sebagai inti etika bisnis adalah kesadaran bahwa perusahaan tidak hanya memiliki kewajiban ekonomi dan legal terhadap pemegang saham (stakeholder) saja, tetapi juga memiliki kewajiban sosial terhadap stakeholders seperti pemerintah, customers, investor, masyarakat, pegawai dan bahkan competitor. Stakeholder theory berpandangan bahwa perusahaan harus melakukan pengungkapan sosial sebagai salah satu tanggung jawab kepada para stakeholder.

CV. Bagas Tirta Utama menjalankan program CSR dengan cara bertanggungjawab mengurangi dampak lingkungan, memberikan bantuan kepada masyarakat dengan cara bekerja sama dalam membersihkan lingkungan sekitar, membuka lapangan pekerjaan bagi masyarakat, memberikan bantuan kepada masyarakat pada saat upacara keagamaan, 
program ini bertujuan untuk mempererat hubungan antara masyarakat, pegawai, dan perusahaan.

Berdasarkan hasil pembahasan terhadap peranan CSR (Corporate Social Responsibility) pada perusahaan Air Melya CV. Bagas Tirta Utama dalam kaitannya dengan peningkatan laba usaha perusahaan bahwa CSR berpengaruh signifikan terhadap laba perusahaan pada CV. Bagas Tirta Utama. Besarnya pengaruh CSR terhadap perusahaan dapat dilihat dari laporan tahunan. Pada tahun 2013 perusahaan memiliki pendapatan sebesar Rp. 300.000.000. Pada tahun 2014 dilihat dari laporan tahunan perusahaan mengalami sedikit kenaikan sebesar Rp. 305.000.000, karena perusahaan belum melakukan tanggung jawab sosial perusahaan. Setelah perusahaan melakukan tanggung jawab sosial perusahaan dapat dilihat dari laporan tahunan perusahaan pada tahun 2015 dan 2016 perusahaan mengalami peningkatan yang cukup signifikan yaitu sebesar Rp. 350.000.000 dan Rp. 370.000.000.

Dari serangkaian kegiatan CSR tersebut perusahaan juga dapat meningkatkan konsumen dan laba usahanya, dan merupakan suatu upaya perusahaan CV. Bagas Tirta Utama dalam menjalin hubungan antara perusahaan, karyawan, dan masyarakat, serta lingkungan sekitar perusahaan tersebut. Agar perusahaan ini bisa membantu masyarakat dalam penyediaan pangan yaitu air minum dalam kemasan.

\section{Simpulan dan Saran}

Hasil penelitian menunjukan bahwa 1) CV. Bagas Tirta Utama menerapkan CSRnya dalam bentuk program-programnya dengan bermitra bersama masyarkat dan karyawan. 2) Program CSR tersebut juga dilaksanakan untuk melestarikan lingkungan dan menjaga perekonomian masyarakat. 3) Dari serangkaian kegiatan CSR tersebut perusahaan juga dapat meningkatkan konsumen dan laba usahanya, dan merupakan suatu upaya perusahaan CV. Bagas Tirta Utama dalam menjalin hubungan antara perusahaan, karyawan, dan masyarkat, serta lingkungan sekitar perusahaan tersebut. 


\section{Daftar Pustaka}

Audrey, Sulvian Bella, 2009, "Hubungan Corporate Social Responsibility Terhadap Kinerja Keuangan Pada PT Indofood Sukses Makmur Tbk". Skripsi, Universitas Atmajaya.

Belkaoui dan Ahmad Riahi. 2005. Teori Akuntansi. Jakarta: Salemba Empat.

Buchari, Alma. 2006. Pengantar Bisnis. Bandung: Alfabeta.

Buba zeth, 2011, "Pengaruh Corporate Social Responsibility Terhadap Kinerja Perusahaan Pada PT Sinar Sosro Di Kota Makassar", Skripsi, Universitas Negeri Makassar.

Darwin, Ali, 2006, "Penerapan Sustainability Reporting di Indonesia", Konvensi Nasional Akuntansi V, Program Profesi Lanjutan, Yogyakarta.

Hadi, Nur. 2011, Corporate Sosial Responsibility, Yogyakarta: Graha IImu.

Kartini, Dwi, 2009, Corporate Sosial Responsibility, Jakarta: Refika Aditama.

Khasali, Reinald, 2007, “Industri Berwawasan Lingkungan: Antara Kebutuhan dan Politisi", Media Akuntansi, No.25/th. V.

Kurnia Darwis, 2013, "Pengaruh Pengungkapan CSR Terhadap Kinerja Keuangan Pada Industri Perbankan Yang Tercatat Pada Bursa Efek Indonesia", Skripsi, Universitas Hasanuddin.

Mapisangka, Andi, 2009, "Implementasi CSR Terhadap Kesejahteraan Hidup Masyarakat", JESP Vol I, No. 1.

Mulyadi, 2001, Akuntansi Manajemen: Konsep, Manfaat dan Rekayasa, Edisi Tiga, Jakarta: Salemba Empat.

Scott, W.R. 1997. Financial Accounting Theory. New Jersey Prentice-Hall International. A. Simon \& Schuster Company. Upper Saddle. River.

Susiloadi, Priyanto, 2008, "Implementasi Corporate Sosial Responsibility Untuk Mendukung Pembangunan Berkelanjutan", Spirit Publik, Vol.4 No. 2.

Undang-Undang Nomor 40 Tahun 2007 tentang Perseroan Terbatas (UU PT).

Untung, H.B. 2008, Corporate Sosial Responsibiity, Jakarta: Sinar Grafika.

Wibisono, Yusuf, 2007, Membedah Konsep dan Aplikasi CSR (Corporate Social Responsibility), Gresik: Fascho Publishing. 